\title{
RANCANG ULANG PENGENDALIAN MUTU PRODUK PADA INDUSTRI KOMPONEN SEPEDA MOTOR MENUJU ZERO DEFECT UNTUK MENCAPAI OPTIMALISASI MANUFAKTUR
}

\author{
TEDI DAHNIAR, KARTIKO EKO P \\ Jurusan Teknik Industri Fakultas ,Teknik Institut Sains dan Teknologi Nasional \\ Tedi.dzagen@gmail.com
}

\begin{abstract}
PT. Indonesia Nippon Seiki is a manufacturing company that has been implementing quality control system, not necessarily achieve zero defect. This study aims to improve the quality control system to zero defect. The study was conducted on a company that produces two-wheeled automotive parts. The research applied Failure Methode and Effect Analysis (FMEA) method to identify the main problem of product defect, its cause and its impact. FMEA is conducted using 3 years production data on 3 assembly plants with field observation and interviews with key personnel in each factory. The results showed that the improvement needs to be done on the elements of the machine, human, methods and environment, after the improvement is done on the four elements of the product failed or reject and claim can be derived.
\end{abstract}

Keywords: Failure Mode and Effect Analysis (FMEA), Reject, Zero Defect

\section{PENDAHULUAN}

Industri alat transportasi darat merupakan industri yang berkembang dengan pesat dalam beberapa tahun terakhir ini. Semakin banyak jumlah pabrik perakitan maupun komponen alat transportasi darat (khususnya otomotif) di Indonesia. Pertumbuhan ini dipacu oleh peluang pasar alat transportasi darat yang besar di Indonesia. Sebagai negara yang memiliki jumlah penduduk yang besar, Indonesia menjadi sasaran pemasaran produk yang baik, utamanya alat transportasi. Meskipun alat transportasi umum telah tersedia, namun kecenderungan untuk memiliki kendaraan pribadi masih tetap tinggi. Hal ini dipicu oleh kemudahan dan fleksibilitas waktu yang diperoleh dengan memiliki kendaraan pribadi.

\section{LANDASAN TEORI}

Jumlah motor dan mobil di Jakarta meningkat sebesar 12 persen tiap tahunnya, kata Kepala Bidang Hubungan Masyarakat Polda Metro Jaya, Komisaris Besar Polisi Martinus Sitompul Jakarta (ANTARA News 2014). Berdasarkan data yang dikeluarkan oleh Direktorat Lalu Lintas Polda Metro Jaya, jumlah kendaraan bermotor di Jakarta dan sekitarnya bertambah sebanyak 5.500 hingga 6.000 unit kendaraan per hari, Ia mengatakan, jumlah tersebut didominasi oleh pertambahan sepeda motor yang mencapai 4.000 hingga 4.500 per hari. Sedangkan kendaraan roda empat mengalami pertumbuhan sebanyak 1.600 unit per hari.
Pertumbuhan industri ini memberikan peluang penyerapan tenaga kerja yang lebih besar. Perkembangan industri hilir (perakitan) memicu pertumbuhan industri hulu dan antara sebagai pendukungnya. Selain penanaman modal asing, saat ini juga telah bermunculan industri dalam negeri (lokal) dalam bidang industri alat transportasi darat. Selain itu industri komponen pendukung sebagai after sales services juga semakin banyak. Dengan demikian diharapkan ke depannya industri alat transportasi darat dalam negeri akan terus berkembang dan mampu bersaing dengan industri luar negeri sehingga ketergantungan terhadap produk luar negeri dapat berkurang.

Dari uraian Kombes Polisi Martinus Sitompul dapat disimpulkan bahwa produksi pertumbuhan motor sangat tinggi maka penulis mengambil kasus dalam tesis ini khusus mengadakan penelitian dibidang otomotif sepeda motor khususnya komponen sepeda motor. 



Motor

Gambar 1 Trend Produksi Mobil dan

Seperti yang terlihat pada data diatas volume pertumbuhan dalam penjualan sepeda motor terlihat meningkat fluktuatif dari tahun ketahunnya karena sifat orang indonesia yang konsumtif serta di tambah lagi industri outomotif, di indonesia yang tidak memiliki keterbatasan dalam memproduksi kendaraan membuat masyarakat indonesia selalu ingin memiliki produk-produk yang di keluarkan oleh perusahaan-perusahaan outomotif, terutama kendaraan roda dua.

Dari data yang sudah terhimpun di Media Data (2010), ternyata perkembangan industri kendaraan bermotor di dalam negeri masih belum sepenuhnya ditopang oleh industri komponen. Hal ini nampak dari masih tingginya komponen impor terutama dari masing-masing negara pemilik teknologi atau negara prinsipalnya. Sejak diberlakukannya kebijakan penanggalan (deletion program), industri komponen di dalam negeri terus berkembang (Media Data 2010) untuk memenuhi kebutuhan komponen original equipment manufacturing (OEM) pada industri perakitan dalam negeri maupun untuk komponen pengganti (replacement).

Industri komponen otomotif di Indonesia berkembang sejak adanya kebijakan pemerintah mengenai ketentuan penggunaan komponen lokal (tahun 1976). produktifitas terhadap produk tersebut meningkat serta perusahaan-perusahaan tersebut semakin berinovasi untuk membuat produknya menarik perhatian konsumennya. Karena sifatnya yang konsumtif tersebut membuat sebagian masyarakat indonesia sangat ingin membeli atau memiliki produk-produk tersebut, dalam pembelian produk tersebut masyarakat indonesia tidak di batasi pula berapa banyak mereka membeli produk itu.

PT. INS merupakan salah satu pabrik yang memproduksi komponen kendaraan bermotor yang sadar bahwa dunia otomotif merupakan bisnis yang amat kritis dengan pasar, dikarenakan sekarang ini kendaraan merupakan hal yang sangat penting, dan juga di tuntut untuk dapat meningkatkan kualitas mutu dari produk-produknya tersebut dengan Standar Mutu Internasional (ISO) untuk para pemasoknya. Dalam mengantisipasi tuntutan dari pelanggan dan pasar PT. INS melakukan peningkatan manajemen dengan menerapkan Quality Management System ISO 9001:2008. Selama pelaksanaan Sistem Manajemen Mutu ISO 9001:2008 di PT. INS ternyata masih sering terjadi kesalahan proses dan kinerja yang yang tidak sesuai dengan ketentuan yang ditetapkan perusahaan.

Menurut (Ciptani,1999) suatu produk yang berkualitas tidak hanya produk yang mempunyai performance yang baik tapi juga harus memenuhi kriteria kepuasan konsumen. Hal ini merupakan sesuatu yang sangat penting bagi perusahaan terutama dalam persaingan bisnis yang sangat ketat. Maka dari itu untuk mengurangi produk cacat yang secara tidak langsung berpengaruh terhadap keuntungan perusahaan, penulis menganalisa sistem pengendalian kualitas yang diterapkan PT. INS secara menyeluruh khususnya dengan salah satu metode pengendalian kualitas yaitu dengan menggunakan metode FMEA.

FMEA (Failure Mode and Effect Analysis) pertama kali dimunculkan dari sebuah studi yang dilakukan oleh NASA pada tahun 1963. FMEA kemudian tersebar pada industri manufaktur mobil, yang digunakan untuk mengukur dan menunjukkan kemungkinan potensi - potensi cacat pada tahap perancangan suatu produk, sehingga produk yang cacat tidak sampai ke tangan konsumen.

FMEA (Failure Mode and Effect Analysis) pertama kali dimunculkan dari sebuah studi yang dilakukan oleh NASA pada tahun 1963. FMEA kemudian tersebar pada industri manufaktur mobil, yang digunakan untuk mengukur dan menunjukkan kemungkinan potensi - potensi cacat pada tahap perancangan suatu produk, sehingga produk yang cacat tidak sampai ke tangan konsumen.

Secara umum, FMEA (Failure Modes and Effect Analysis) didefinisikan sebagai sebuah teknik yang mengidentifikasi tiga hal, yaitu : 
1. Penyebab kegagalan yang potensial dari sistem, desain produk, dan proses selama siklus hidupnya.

2. Efek dari kegagalan tersebut.

3. Tingkat kekritisan efek kegagalan terhadap fungsi sistem, desain produk, dan proses.

FMEA merupakan dokumen yang berkembang terus. Semua pembaharuan dan perubahan siklus pengembangan produk dibuat untuk produk atau proses. Perubahan ini dapat dan sering digunakan untuk mengenal mode kegagalan baru. Mengulasn memperbaharui FMEA adalah penting terutama ketika:

1. Produk atau proses baru diperkenalkan.

2. Perubahan dibuat pada kondisi operasi produk atau proses diharapkan berfungsi.

3. Perubahan dibuat pada produk atau proses (dimana produk atau proses berhubungan). Jika desain produk dirubah, maka proses terpengaruh begitu juga sebaliknya.

4. Konsumen memberikan indikasi masalah pada produk atau proses.

5. masalah pada produk atau proses.

\section{Persiapan Penelitian}

Pengumpulan data merupakan hasil penelitian yang diperoleh dari data historis perusahaan sebagai dasar pengukuran kondsisi aktual, serta data hasil observasi, wawancara, dokumentasi, studi pustaka, dan eksperimen yang dilakukan untuk mendukung penelitian.

Dalam penelitian permasalahan yang diambil adalah mengenai claim yang terjadi dan kecacatan (NG) produksi yang terjadi pada tiap departemen. Untuk data-data claim dan kecacatan produk diperoleh berdasarkan pengamatan dan pengecekan langsung pada pada masalah yang terjadi tersebut.

Sebagai bahan analisa penulis memperoleh pengumpulan data Claim dan data NG produk periode 2014 sampai 2016 dimana setelah melakukan pengamatan dan pengecekan secara langsung di departemen assembling 1, assembling 2 dan assembling 3 yang bermasalah dan terdapat banyak produk yang cacat efek proses dan human error dan merupakan yang tertinggi. Adapun data yang diperoleh adalah berdasarkan pengamatan harian yang dilakukan setiap harinya oleh penulis serta operator mesin.

Selain menjadi data NG beberapa jenis cacat juga menimbulkan claim/complain dari costumer yang memerlukan cost yang cukup tinggi untuk mengganti claim tersebut. Untuk itu sangatlah penting untuk menurunkan persentase claim dan NG/cacat dari produk yang dihasilkan serta membuat lost cost yang terjadi menjadi rendah atau hilang.

\begin{tabular}{|c|c|c|c|}
\hline \multirow{5}{*}{ 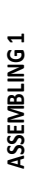 } & ITEM NG & TOTAL & $\%$ ACC \\
\hline & DIAL DESIGN GORES & 6499 & $82,2 \%$ \\
\hline & MOVEMENT SPEED MINUS & 3467 & $86,6 \%$ \\
\hline & NG FUEL METER & 309 & $90,5 \%$ \\
\hline & & & \\
\hline
\end{tabular}

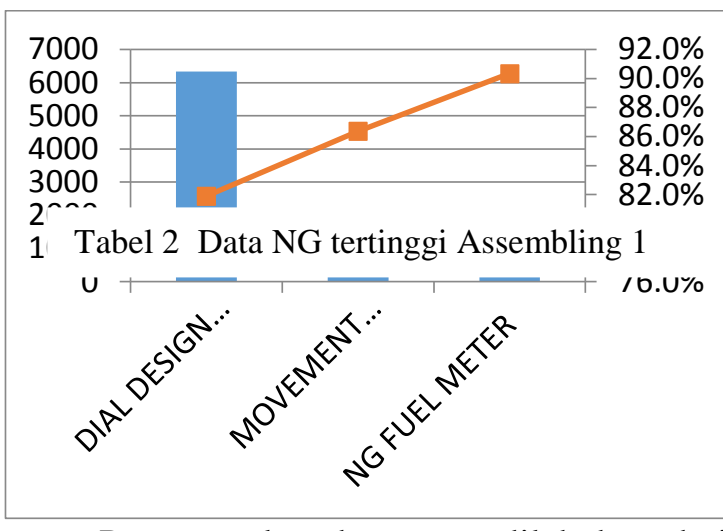

Pengumpulan data yang dilakukan dari 2014 sampai dengan 2016 ternyata dapat diketahui jenis - jenis kegagalan proses yang terdapat di assembling 1 dan yang palilng tertinggi adalah Dial design gores sebesar 6499pcs.

Tabel 3 Data Kegagalan Proses Assembling 2

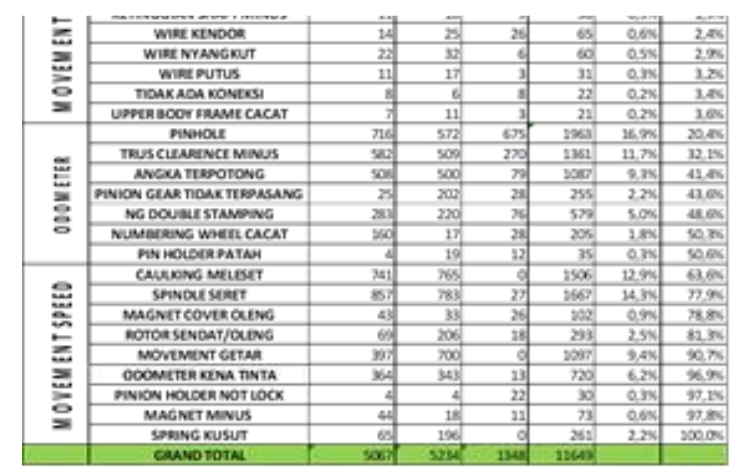

Tabel 4 Data NG tertinggi Assembling 2 


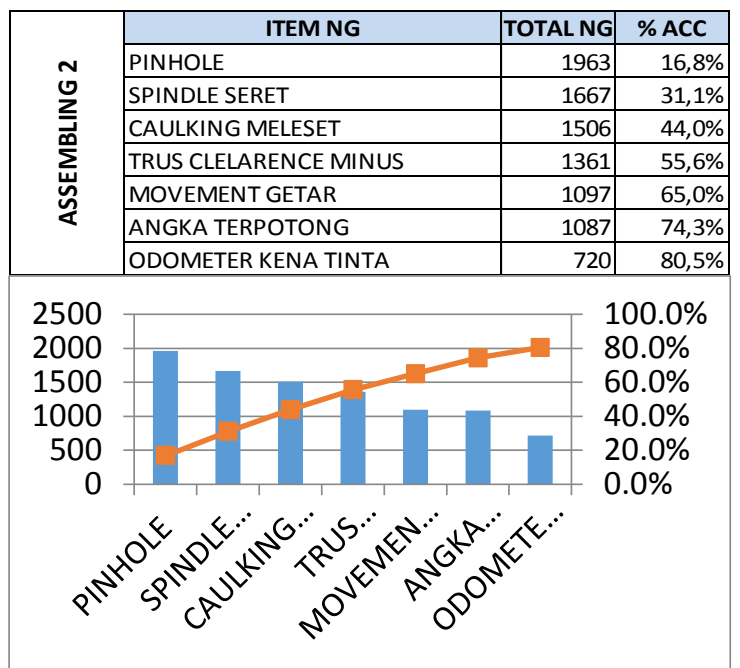

Pengumpulan data yang dilakukan dari 2014 sampai dengan 2016 ternyata dapat diketahui jenis - jenis kegagalan proses yang terdapat di assembling 2 dan yang palilng tertinggi adalah pinhole sebesar 1963pcs.

\begin{tabular}{|l|l|l|l|l|l|l|}
\hline IтеM NG & 2014 & 2015 & 2016 & TOTAL & $\%$ & \% Ace \\
\hline
\end{tabular}

Tabel 5 Data Kegagalan Proses Assembling 3

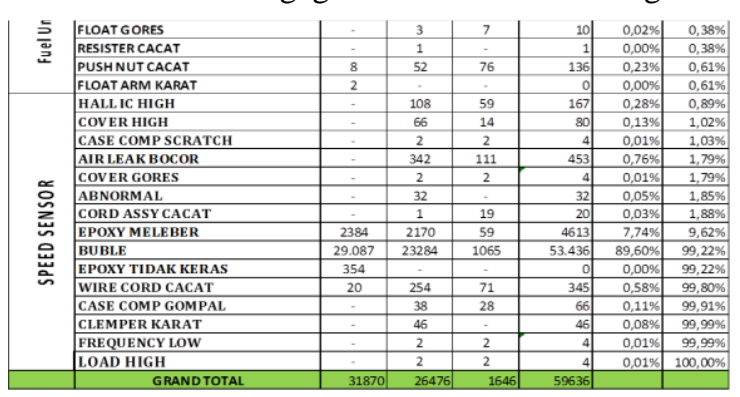

Tabel 6 Data NG tertinggi Assembling 3

\begin{tabular}{|c|c|c|c|c|c|c|}
\hline & 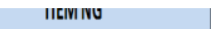 & 2014 & LU1J & QN10 & IUIAL & 0 \\
\hline & DIALDESIGNGORES & 3587 & 1913 & 999 & 6499 & $82,2 \%$ \\
\hline$\rightarrow$ & UPPER CASE GORES & 23 & 102 & 6 & 131 & \begin{tabular}{|l|r|}
$1,7 \%$ & $83,8 \%$ \\
\end{tabular} \\
\hline 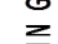 & REFLECTOR GORES & 180 & 97 & 3 & 280 & $87,4 \%$ \\
\hline 二 & NG FUEL METER & 140 & 146 & 23 & 309 & \begin{tabular}{l|l|}
$3,9 \%$ & $91,3 \%$ \\
\end{tabular} \\
\hline$\Sigma$ & DIAL TERKENA LEM & 190 & 36 & 7 & 233 & $94,2 \%$ \\
\hline س & MOVEMENTSPEED BENGKOK & 14 & 4 & 6 & 24 & \begin{tabular}{l|r|}
$0,3 \%$ & $94,5 \%$ \\
\end{tabular} \\
\hline$\approx$ & MOVEMENT SPEED MINUS & 317 & 21 & 8 & 346 & \begin{tabular}{l|l|}
$4,4 \%$ & $98,9 \%$ \\
\end{tabular} \\
\hline & UNDER CASEPATAH & 72 & 11 & 3 & 86 & \begin{tabular}{l|l|}
$1,11 \%$ & $100,0 \%$ \\
\end{tabular} \\
\hline & TOTAL NG PROSES & 4523 & 2330 & 1055 & 7908 & \\
\hline $\begin{array}{l}m \\
0 \\
0\end{array}$ & ITEM NG & & & & TOTAL & $\%$ ACC \\
\hline$\underline{\underline{m}}$ & Buble & & & & 53436 & $89,6 \%$ \\
\hline$\sum_{u}$ & Epoxy meleber & & & & 4613 & $97,3 \%$ \\
\hline y & Air leak bocor & & & & 453 & $98,1 \%$ \\
\hline 60000 & & & & & & $100,0 \%$ \\
\hline 50000 & & & & & & $98,0 \%$ \\
\hline 40000 & & & & & & \\
\hline 30000 & & & & & & $92,0 \%$ \\
\hline 20000 & & & & & & $90,0 \%$ \\
\hline 10000 & & & & & & $86,0 \%$ \\
\hline & Buble & Epox & eleber & & leak bocor & $84,0 \%$ \\
\hline
\end{tabular}

Pengumpulan data yang dilakukan dari 2014 sampai dengan 2016 ternyata dapat diketahui jenis - jenis kegagalan proses yang terdapat di assembling 2 dan yang palilng tertinggi adalah pinhole sebesar 53436pcs.

Berdasarkan mode-mode kegagalan pada tabel diatas penulis dapat menetukan dimana penulis akan melakukan penelitian berdasarkan kegagalan proses tertinggi seperti pada :

1. Assembly $1 \Rightarrow$ Dial design gores.

2. Assembly $2 \Rightarrow$ Pinhole.

3. Assembly $3 \Rightarrow$ Buble

\section{Observasi Menggunakan FMEA}

Observasi dan pengambilan data yang dilakukan adalah 1 shift dengan 9 jam kerja selama 3 minggu pada setiap departemen dimana pada setiap harinya dilakukan pengamatan untuk mencari akar permasalahan yang terjadi, dalam observasi FMEA harus dilakukan dengan membentuk tim dengan pengalaman yang relevan dan otoritas yang diperlukan, tim yang penulis bentuk terdiri dari 4 orang yaitu :

1. Bapak Ahmad Taftahul QC line Assembling 1

2. Bapak Andi Setiawan QC line Assembling 2

3. Bapak Azhari Alim QC line Assembling 3

4. Tedi Dahniar sebagai peneliti

Dari mode-mode kegagalan yang menyebabkan cacat tersebut maka perhitungan RPN pada tabel dapat dideskripsikan sebagai berikut

1. Dial design gores (gelembung udara) adalah cacat yang diakibatkan oleh penanganan handling yang tidak baik dikarenakan peletakan dial design pada bucket didisusun berhimpitan sehingga dapat mengakibatkan NG gores. Efek dari dial design gores adalah apabila terkena cahaya dari bulp lampu yang ada pada speedometer maka akan terlihat cahaya yang tembus dan dapat dilihat oleh Costumer. Berdasarkan hal tersebut bobot mode kegagalan nya adalah :

a. Severity adalah 8 karena akibat yang ditimbulkan sangat berpengaruh terhadap kualitas dan kepuasan 
costumer. Dial design gores akan terlihat apabila terpapar cahaya bulp lampu oleh pemakai.

b. Occurance adalah 5 dengan fakta dilapangan dimana jumlah produk yang NG adalah 6334 selama periode 2014 - agustus 2016 dari 1.000.000 produk yang dihasilkan 1 tahun maka masuk dalam rating 5 dalam standar Occurance.

c. Detection adalah 10 karena berdasarkan fakta dilapangan dari hasil penelitian tim yang penulis bentuk masih banyak terdapat NG dial design gores dan tidak ada alat deteksi dilapangan maka tim memberikan rating 10 untuk detection.

d. Dari poin-point diatas bahwa nilai severity 7 , nilai occurance 3 , dan detection 10 maka perhitungan untuk nilai RPN nya adalah 210, ini merupakan hasil perkalian dari $\mathrm{S}, \mathrm{O}$,dan D yang dirurmuskan sebagai berikut :

$$
\begin{gathered}
R P N=S \times O \times D=8 \times 5 \times 10 \\
=400
\end{gathered}
$$

2. Pinhole (lubang tembus pandang) adalah cacat yang diakibatkan oleh udara yang keluar dari ionizer sebagai pembersih kotoran mengandung minyak yang kemudian menempel pada foil dan part dan menyebabkan pinhole pada hasil stamping. Berdasarkan hal tersebut bobot mode kegagalan nya adalah :

a. Severity adalah 7 karena akibat yang ditimbulkan berpengaruh sedang pada produksi yang berjalan. Pinhole yang terjadi akan meninggalkan bercak titik pada numbering wheel dan akan terlihat oleh pemakai .

b. Occurance adalah 3 dengan fakta dilapangan dimana jumlah produk yang NG adalah 1963 selama periode 2014 - agustus 2016 dari 1.000.000 produk yang dihasilkan 1 tahun maka masuk dalam rating 3 dalam standar Occurance.

c. Detection adalah 10 karena berdasarkan fakta dilapangan dari hasil penelitian tim yang penulis bentuk masih banyak terdapat pinhole pada numbering wheel dan tidak ada alat deteksi dilapangan maka tim memberikan rating 10 untuk detection.

d. Dari poin-point diatas bahwa nilai severity 7 , nilai occurance 3 , dan detection 10 maka perhitungan untuk nilai RPN nya adalah 210, ini merupakan hasil perkalian dari S,O,dan D yang dirurmuskan sebagai berikut :

$$
\begin{gathered}
R P N=S \times O \times D=7 \times 3 \times 10 \\
=210
\end{gathered}
$$

3. Bubble (gelembung udara) adalah cacat yang diakibatkan oleh udara yang keluar dari ionizer sebagai pembersih kotoran mengandung minyak yang kemudian menempel pada foil dan part dan menyebabkan pinhole pada hasil stamping. Berdasarkan hal tersebut bobot mode kegagalan nya adalah :

a. Severity adalah 8 karena akibat yang ditimbulkan sangat berpengaruh dibuktikan dengan fakta dilapangangan bahwa cacat yang terjadi dapat menyebabkan kebocoran terhadap produk. Bubble yang terjadi akan membuat fungsin dari produk terganggu.

b. Occurance adalah 7 dengan fakta dilapangan dimana jumlah produk yang NG adalah 53379 selama periode 2014 - agustus 2016 dari 1.000.000 produk yang dihasilkan 1 tahun maka masuk dalam rating 7 dalam standar Occurance.

c. Detection adalah 10 karena berdasarkan fakta dilapangan dari hasil penelitian tim yang penulis bentuk masih banyak terdapat pinhole pada numbering wheel dan tidak ada alat deteksi dilapangan maka tim memberikan rating 10 untuk detection.

d. Dari poin-point diatas bahwa nilai Severity 7, nilai Occurance 3, dan Detection 10 maka perhitungan untuk nilai RPN nya adalah 210, ini merupakan hasil perkalian dari $\mathrm{S}, \mathrm{O}$,dan D yang dirurmuskan sebagai berikut :

$R P N=S \times O \times D=8 \times 7 \times 10=$ 560

Berdasarkan pengolahan data hang dilakukan dengan metode Failure Methode and Effect Analysis (FMEA) didapatkann hasil berdasrkan penilaian Risk Priority Number 
(RPN), proses yang mendapatkan nilai tertinggi dari 3 departemen adalah Epoxy Filling sebesar 560 dari Assembling 3, Justing sebesar 400 dari Assembling 1,dan Hotstamp sebesar 210 dari Assembling 2, ketiga mode kegagalan tersebut mendapatkan peringkat RPN tertinggi karena mempunyai tingkat kegagalan mayor.

Dari hasil obervasi dengan tempat penyebab timbulnya kegagalan yaitu penyebab khusus (Special Causes Variation) yaitu kejadian diluar sistem manajemen kualitas yang mempengaruhi variasi dalam sistem itu seperti

\section{Membuat Perbaikan}

Kegagalan proses/defect

Mesin / Alat

1. Dial design gores

2. Pinhole

3. Bubble

Kontrol sistem yang sudah ada

a. Pada defect dial design gores selama ini dilakukan dengan melakukan cek visual $100 \%$ terhadap semua dial design tanpa memperhatikan proses yang lain.

b. Pada defect pinhole selama ini dilakukan dengan melakukan cek visual $100 \%$ pada setiap proses di line odometer.

c. Pada defect bubble selama ini dilakukan dengan melakukan cek visual $100 \%$ setelah proses filling manual

Kontrol baru yang dibuat

a. Untuk mengurangi/ menghilangkan defect dial design gores dilakukan setting ulang timer press pointer fuel dan waktu press pointer diperlambat

b. Untuk mengurangi/menghilangkan defect pinhole dilakukan preventive harian ionizer/filter untuk membersihkan udara dari segala kotoran dan oil

c. Untuk menghilangkan defect bubble dibuatkan mesin filling otomatis agar hasil dari filling dari pencampuran pelnox dan pelcure tidak menimbulkan bubble

d. Untuk mengontrol pekerjaan dipasang kamera untuk mengawasi semua operator yang sedang bekerja.

\section{Manusia}

Kontrol sistem yang sudah ada

a. Training dilakukan hanya ketika awal masuk kerja dipabrik

b. WI hanya dibaca tanpa dipahami

Kontrol baru yang dibuat

a. Untuk mengetahui kemampuan aktual operator dibuatkan cek sheet kepatuhan untuk tiap operator agar mengetahui faktor manusia, mesin/peralatan, material, lingkungan dan metode kerja.

Penyebab dari special causes pada perusahaan bersumber pada umur mesin yang sudah tua dan preventive mesin yang tidak maksimal dilakukan, konsistensi pekerja yang menyebabkan kurangnya konsentrasi dan ketelitian yang menyebabkan kegagalan, lingkungan kerja yang tidak kondusif seperti banyaknya debu-debu kecil yang bertebaran diarea kerja, metode kerja yang tidak sesuai dengan standar yang berlaku.

perkembangan kemampuannya dalam bekerja

b. Diadakan training proses di line bersangkutan/3bulan

c. WI dibaca 2 kali setiap awal proses dimulai pagi dan habis istirahat mkan siang..

d. Melakukan evaluasi terhadap kemampuan operator

e. Melakukan evaluasi terhadap leader

Methode

Kontrol sistem yang sudah ada

a. Untuk dial design gores selama ini dilakukan cek visual $100 \%$ terhadap dial design tanpa memerhatikan kecepatan dan proses yang lain

Kontrol baru yang dibuat

a. Diberikan marking diatas conveyor untuk memberi jarak saat peletakan dial design agar tidak ada pergesekan.

b. Merubah settingan waktu pada proses Vibration yang semula 60 detik menjadi 120 detik untuk menghilangkan NG bubble

\section{Lingkungan}

Kontrol baru yang dibuat

Memberi pelindung dari bahan plastik/fiber pada mesin hot stamp agar terlindung dari debu untuk menghilangkan NG pinhole.

Setelah dilakukan observasi dan penerapan dengan menggunakan metode FMEA ternyata berpengaruh sangat baik terbukti dengan menurunnya kegagalan proses di setiap departemen dan memperbaiki sistem pengendalian mutu yang sudah ada.

Tabel 7 Data NG Assembling 1 (Setelah Perbaikan) 


\begin{tabular}{|c|c|c|c|c|c|c|}
\hline & ITEM NG & OCT & NOV & DEC & TOTAL & AVERAGE \\
\hline \multirow{8}{*}{$\begin{array}{l}-1 \\
0 \\
z \\
z \\
\sum_{u}^{0} \\
u \\
n\end{array}$} & DIALDESIGN GORES & 15 & . & & & 15 \\
\hline & UPPER CASE GORES & ${ }^{\circ}$ & . & & . & - \\
\hline & REFLECTOR GORES &. & . & & & . \\
\hline & NG FUEL METER & . & . & & & . \\
\hline & DIAL TERKENA LEM & . & . & & & \\
\hline & MOVEMENT SPEED BENGKOK & & & & & \\
\hline & MOVEMENT SPEED MINUS & $\cdot$ & . & & & . \\
\hline & UNDER CASE PATAH & 2 & 1 & & & 4 \\
\hline & OTAL NG PROSES & 17 & & & & \\
\hline
\end{tabular}

Tabel 8 Data NG Assembling 2 (Setelah Perbaikan)



Tabel 8 Data NG Assembling 2 (Setelah Perbaikan)

\begin{tabular}{|c|c|c|c|c|c|c|}
\hline \multirow{8}{*}{ 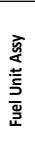 } & FLOAT GOMPAL & - & - & - & - & - \\
\hline & LOCK PATAH & - & - & - & - & - \\
\hline & BODY BURRY & 21 & - & - & 21 & 7 \\
\hline & TERMINAL NONGOL ( Model FU5) & & - & - & & - \\
\hline & FLOAT GORES & - & - & - & - & \\
\hline & RESISTER CACAT & 10 & - & - & 10 & 3 \\
\hline & PUSH NUT CACAT & - & - & - & - & - \\
\hline & FLOAT ARM KARAT & - & 2 & - & 2 & 1 \\
\hline \multirow{16}{*}{ 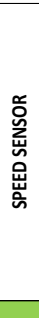 } & HALL IC HIGH & - & - & - & - & - \\
\hline & COVER HIGH & - & - & - & - & - \\
\hline & \begin{tabular}{|l} 
CASE COMP SCRATCH \\
\end{tabular} & & - & - & - & - \\
\hline & AIR LEAK BOCOR & 2 & - & - & 2 & 1 \\
\hline & \begin{tabular}{|l|} 
COVER GORES \\
\end{tabular} & - & - & - & - & - \\
\hline & \begin{tabular}{|l} 
ABNORMAL \\
\end{tabular} & - & - & - & - & - \\
\hline & \begin{tabular}{|l} 
CORD ASSY CACAT \\
\end{tabular} & - & - & - & - & - \\
\hline & \begin{tabular}{|l} 
EPOXY MELEBER \\
\end{tabular} & - & - & - & - & - \\
\hline & BUBLE & - & 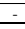 & - & - & - \\
\hline & EPOXY TIDAK KERAS & - & & - & & \\
\hline & WIRE CORD CACAT & - & 2 & - & 2 & 1 \\
\hline & CASE COMP GOMPAL & - & - & - & - & - \\
\hline & \begin{tabular}{|l|} 
CLEMPER KARAT \\
\end{tabular} & 4 & - & - & 4 & 1 \\
\hline & FREQUENCY LOW & - & - & - & - & - \\
\hline & LOAD HIGH & - & - & - & - & - \\
\hline & GRAND TOTAL & & & & 4. & \\
\hline
\end{tabular}

\section{DAFTAR PUSTAKA}

Aryanto, Andi, (2015) “Analisis Kecacatan Produk Fillet SkinOn Red Mullet Dengan The Basic Seven Tools Of Quality Dan usulan Perbaikannya Menggunakan Metode FMEA pada PT. Holi Mina Jaya” Jurnal Manajemen Teori dan Terapan Tahun 8. No. 1, April 2015

Dewayana, Triwulandari S (2012) "Peluang dan Tantangan Industri Komponen Otomotif Indonesia “ Jurnal Program Magister Teknik Industri
Fakultas Teknologi Industri Universitas Trisakti

Effendi, Syafwansyah (2015) “ Perbedaan Risk Priority Number dalam Failure Mode And Effects Analysis (FMEA) Sistem Alat Berat Heavy Duty Truck HD 785-7 "Spektrum Industri, 2015, Vol. 13, No. 1, 1 114

FMEA Fourth Edition (2008) "Potential Failure Mode and Effect Analysis" Chrysler LLC, Ford Motor Company, General Motor Corporation.

Gaikindo, (2005 - 2016) “ Domestic Auto Production By Category January 2005 - November 2016 “ The Association Of Indonesia Automotive Industries

Gasperz, Vincent. 2002. Pedoman Implemntasi Six Sigma Terintegrasi dengan ISO 9001:2000, MBNQA dan HCCP. PT Gramedia Pustaka Utama. Jakarta.

Gasperz, Vincent. 2003. ISO 9001:2000 and Continual Quality Improvement. PT Gramedia Pustaka Utama. Jakarta.

Gasperz, Vincent. 2005. Manejemen Kualitas. PT Gramedia Pustaka Umum. Jakarta

Parasha, Shikha (2015) "Goal of Modern Industries: "Zero Defects, Zero Effect " International Journal of Engineering Research and General Science Volume 3, Issue 2, MarchApril, 2015 ISSN 2091-2730

Puspitasari , Nia Budi (2014) "Penggunaan FMEA Dalam Mengidentifikasi Resiko Kegagalan Proses Produksi Sarung ATM (Alat Tenun Mesin) (Studi Kasus PT. Asaputex Jaya Tegal) “Jurnal J@TI Undip, Vol IX, No 2, Mei 2014

Kristyanto, Raka (2015) “ Analisis Risiko Operasional Pada Proses Produksi Gula Dengan Menggunakan Metode Multi Attribute Failure Mode Analysis (MAFMA) (Studi Kasus : PG. Kebon Agung Malang)" Jurnal Rekayasa Dan Manajemen Sistem Industri Vol. 3 NO. 3 Teknik Industri Universitas Brawijaya.

Krishnan, Chinmaya (2015) “ Zero Defect Management - A Study On The 
Relevence In Modern Day s" International Research Journal of Engineering and Technology (IRJET) Volume: 02 Issue: 05

Mayangsari, Diana Fitria (2015) “ Usulan Pengendalian Kualitas Produk Isolator Dengan Metode Failure Methode and Effect Analysis (FMEA) dan Fault Tree Analysis(FTA).

Manger, RyanP. (2014) "Failure Mode and Effect Analysis and Fault Tree Analysis of surface imaged guided cranial radio surgery "

Media Data, (2010). Bisnis Otomotif Indonesia Di tengah Persaingan Pasar Regional.

Media Data, (2010) Direktori Komponen Otomotif di Indonesia. 